\title{
China em transformação: transição e estratégias de desenvolvimento
}

\author{
Changes in China: transition and development strategies
}

MARCOS ANTONIO MACEDO CINTRA EDUARDO COSTA PINTO*

\begin{abstract}
RESUMO: Este artigo examina as atuais estratégias de desenvolvimento da China, que enfrenta um período de transição interna - em virtude das contradições do seu regime de crescimento -, e redefinições das relações com o restante do mundo que vem desencadeando um processo de reconfiguração da ordem mundial (transição internacional). Dois dos principais eixos dessa estratégia chinesa são a ampliação do uso do renminbi no âmbito mundial e a internacionalização do capital chinês por meio dos megaprojetos de infraestrutura, notadamente no entorno asiático.
\end{abstract}

PALAVRAS-CHAVE: China; desenvolvimento; renminbi; infraestrutura.

ABSTRACT: This paper analyses China's the current development strategies. This country has been facing a domestic transition period - resulting from contradictions of its current growth regime - and a redesign of its relations with the rest of the world that has promoting a process of reconfiguration of the world order (international transition). Two major axes of this Chinese strategy are the extension of the usage of renminbi to a global level and the internationalization of the Chinese capital through infrastructure megaprojects, chiefly in Asian surroundings.

KEYWORDS: China; development; renminbi; infrastructure.

JEL Classification: O10; F50.

\section{INTRODUÇÃO}

A economia mundial e o sistema interestatal têm apresentado profundas transformações com a ascensão econômica e política da China nas últimas décadas. A economia

\footnotetext{
* Respectivamente, Técnico de Planejamento e Pesquisa da Diretoria de Estudos e Políticas Macroeconômicas (Dimac) do Instituto de Pesquisa Econômica Aplicada (Ipea). E-mail: marcos.cintra@ ipea.gov.br; Professor do Instituto de Economia da Universidade Federal do Rio de Janeiro e pesquisador do Programa Nacional de Pesquisa para o Desenvolvimento Nacional (PNPD) do Ipea. E-mail: eduardo. pinto@ie.ufrj.br. Submetido: 18/Maio/2015; Aprovado: 15/Abril/2016.
} 
chinesa cresceu $10 \%$ ao ano nos últimos 30 anos, tornando-se a "fábrica do mundo" e gerando uma nova divisão internacional da produção. No plano internacional, a China tem obtido cada vez mais poder no âmbito das instituições multilaterais e das negociações bilaterais com outros países em desenvolvimento e desenvolvidos, projetando o seu poder no tabuleiro geoeconômico e geopolítico asiático e mundial.

Essa trajetória chinesa de desenvolvimento, ainda em construção, e que pressupõe um processo de aprendizado contínuo com avanços e recuos, articula uma estratégia nacional, inserida regional e globalmente, que tem como objetivo tornar a China um país moderno, rico e poderoso. Com isso, as políticas macroeconômica, industrial, de ciência e tecnologia, externa e de segurança são direcionadas pelo Estado para a construção de uma estabilidade política, a melhoria das condições de vida do povo chinês e a reconquista de uma posição internacional autônoma.

Hodiernamente, o desenvolvimento econômico da China encontra-se em um novo período de transição interna em virtude das contradições do regime de crescimento, fortemente concentrado no investimento, que tem gerado desequilíbrios econômicos e sociais. O Estado chinês vem tentando construir um novo regime de crescimento sustentável, articulado à configuração de um Estado de bem-estar com características particulares. Associado a isso, delineiam-se novas relações (financeiras, de investimentos, diplomáticas, de defesa etc.) entre a China e o restante do mundo que vem desencadeando um processo de transição internacional.

Este artigo tem como objetivo analisar essas estratégias de desenvolvimento da China, que enfrenta um período de transformações internas, e redefinições de sua inserção no sistema internacional. Destacam-se as estratégias de expansão do renminbi e de internacionalização do capital chinês que se articulam aos megaprojetos de infraestrutura no entorno asiático e no restante do mundo. Para discutir essas questões, o artigo está organizado em quatro seções após esta breve introdução. Na segunda, realiza-se um panorama dos elementos gerais da estratégia de desenvolvimento da China, marcada por uma nova fase de transição interna e internacional. $\mathrm{Na}$ terceira, detalha-se a estratégia financeira chinesa de expansão de sua moeda para além do seu espaço territorial. Na quarta, discute-se o movimento de internalização do capital chinês por meio dos megaprojetos de infraestrutura transnacional, sobretudo no entorno asiático. E, por fim, na quinta, procura-se alinhavar algumas considerações a título de conclusão.

\section{ELEMENTOS GERAIS DA ESTRATÉGIA DE DESENVOLVIMENTO CHINÊS: UM NOVO PERÍODO DE TRANSIÇÃO}

Após décadas de vertiginoso crescimento e desenvolvimento econômico, o Produto Interno Bruto (PIB) da China, em termo de paridade do poder de compra, alcançou US\$ 18 trilhões (US\$ 10,4 trilhões a preços correntes) em 2014, superando o dos Estados Unidos, de US\$ 17,4 trilhões (em termo de paridade do poder de compra e a preços correntes), segundo o Fundo Monetário Internacional (FMI). Naturalmente, como a população chinesa é mais de quatro vezes maior, seu PIB per capita atingiu US\$ 
13,2 mil em termo de paridade do poder de compra (US\$ 7,6 mil a preços correntes), menos de um quarto do registrado pelos Estados Unidos (US\$ 54,6 mil). De todo modo, a célere trajetória de desenvolvimento - entendido como um processo contínuo de mudança estrutural promovida pela interconexão entre acumulação de capital, progresso técnico e evolução institucional - da China não tem paralelo histórico (Medeiros, 2013; Bresser-Perreira, 2011; Pinto e Gonçalves, 2014). Compreender e dimensionar as transformações dessa sociedade de mais de 1,3 bilhão de habitantes que percebe a si mesma como uma civilização superior, homogênea e com pelo menos 2.300 anos de existência não constitui uma tarefa trivial.

A estratégia militar de aproximação com os Estados Unidos e de afastamento da União das Repúblicas Socialistas Soviéticas (URSS) e a estratégia econômica consolidada no programa das "quatro modernizações" - agricultura, indústria, tecnologia e exército - implementada por Deng Xiaoping, a partir de 1978, fortaleceram o Estado unitário e centralizado chinês, que recuperou sua condição milenar - e imperial (Império do Meio) - de guardião da unidade e do "interesse universal" do território e da civilização chinesa. Para Deng Xiaoping: o desenvolvimento do país deveria estar sempre a serviço da sua política de defesa.

Nesse movimento, o Partido Comunista Chinês (84 milhões de membros), com o controle absoluto sobre o sistema político, restaurou a legitimidade anteriormente personificada no imperador. O Partido Comunista Chinês prolongou e radicalizou uma tradição milenar, ao criar uma espécie de "dinastia mandarim", que segue governando a China segundo os mesmos preceitos morais confucianos do período imperial (Fiori, 2013a, 2013b, 2013c; Aglietta e Bai, 2012; Sinedino, 2012; Kissinger, 2011). Isso requer um alinhamento dos interesses das burocracias sobre o bem público comum, ou seja, a estabilidade política e a garantia de uma renda real crescente e de melhores condições de vida para a população chinesa.

Nesse sentido, o Estado deve dispor de uma estratégia e ter por objetivo o desenvolvimento. A autoridade política deve gerir a economia de forma a produzir mais riqueza, de maneira cada vez mais eficaz, para construir um país moderno, rico e poderoso. As políticas macroeconômica, industrial, comercial, de ciência e tecnologia, de defesa devem estar a serviço da "grande estratégia" social e nacional, e da luta pela conquista ou "reconquista" de uma posição internacional autônoma e preeminente. A planificação estratégica visa à "harmonia”, vale dizer, ao equilíbrio de forças. Nesse sentido, os interesses privados (ou capitalistas) não devem ser poderosos o suficiente para ameaçar a supremacia incontestável do Estado, que mantém um amplo conjunto de empresas e bancos públicos e regula rigorosamente diversas esferas econômicas e as relações com o exterior. Por conseguinte, os mecanismos de mercado - a taxa de juros, a taxa de câmbio, a tributação, os preços - são um instrumento e não um fim em si mesmos; e a abertura econômica assume a condição de eficácia que conduz a uma diretriz operacional, qual seja, alcançar e ultrapassar os concorrentes estrangeiros (Kroeber, 2011, p. 2, Aglietta e Bai, 2012, p. 17).

As reformas promoveram e continuam a promover a transformação conjunta das estruturas socioeconômicas e das instituições. Em um processo recorrente, elas se retroalimentam de seus próprios êxitos e contradições, transmutando-se ao lon- 
go do percurso. Nesse sentido, o significado das reformas não é teleológico, deve ser compreendido como imanentes à prática histórica (Aglietta e Bai, 2012, p. 18). E, graças à permanência da autoridade política - personificada no Partido Comunista Chinês -, as reformas são graduais, orientadas por uma visão de longo prazo, avaliadas de forma pragmática e implementadas de modo experimental, o que pressupõe um processo de aprendizado - com avanços e recuos - contínuo. Exatamente porque se retroalimentam de seus próprios êxitos e contradições, as crises representam momentos de transições de uma fase para outra, contribuindo para o surgimento de novas formas ou novos modelos de organização e de gestão. Em um período de crescimento mais lento, essas contradições se explicitam em desequilíbrios e tensões políticas e sociais que ameaçam a "harmonia". Até que um novo compromisso político-social seja conformado, o poder eventualmente passa de um grupo de interesse para outro, mas permanecem unidos aos objetivos gerais: a legitimidade política, a integridade do Estado unitário e o crescimento da renda da população. Em suma, o Estado chinês - e, por conseguinte, o Partido Comunista Chinês - tem se mostrado altamente flexível e inovador, com extraordinária capacidade de se autocorrigir e de se reinventar (Fiori, 2013a, 2013b, 2013c).

No momento atual, apreende-se que as contradições do "regime de crescimento" desencadeiam um novo período de transição interna. A despeito da desaceleração, a economia chinesa permanece uma das mais dinâmicas do mundo - taxa de crescimento de 7,4\% em 2014 e 6,9\% em 2015 - e continua a criar de 12 milhões a 13 milhões de novos postos de trabalho urbanos ao ano. Porém, com o avanço da taxa de investimento de $40 \%$ do PIB para $47 \%$ do PIB, o crescimento fica desequilibrado - gera capacidade ociosa em inúmeros setores produtivos - e dependente da construção de gigantescas obras de infraestrutura, da expansão do mercado imobiliário, do endividamento das províncias e dos governos locais, bem como da elevada alavancagem de alguns segmentos do setor bancário e não bancário. Busca-se, então, um novo regime de crescimento sustentável, ancorado em um dinamismo menos intensivo em capital e em energia, bem como de um novo contrato social ("um Estado de bem-estar com características chinesas”) para a redução das desigualdades sociais e regionais e a implementação de maior cobertura no sistema de saúde pública e de previdência. A provisão de bens públicos "universais", o desenvolvimento de uma urbanização e uma industrialização com menor impacto sobre o meio ambiente, a ampliação da renda e do consumo da população são os pilares do planejamento estratégico que visam transformar - ou seja, reformar - o regime de crescimento nos próximos anos. ${ }^{1}$ Evidentemente, em um processo de transição emergem conflitos de interesses e geram repercussões políticas para a estrutura do governo. Nas palavras do presidente Xi Jinping (Safatle e Rittner, 2014, grifo nosso):

"É provado pelos fatos que, sem reforma e abertura, não teríamos a China de hoje, para já não dizer do seu futuro. Por meio de reformas, temos

\footnotetext{
${ }^{1}$ Ver World Bank et al., (2012).
} 
resolvido uma série de problemas importantes. Daqui para a frente, insistiremos em usar o mesmo instrumento para superar as dificuldades e desafios no nosso caminho. Temos definido a meta de "dois centenários". Isto é, duplicar até 2020 [quando o Congresso Nacional do Povo celebra seu centenário] o PIB e a renda per capita na base de 2010 e consumar a construção integral de uma sociedade modestamente próspera, e culminar em meados do presente século [2049, quando a República Popular da China comemora seu centenário] a transformação do nosso país em um país socialista moderno, próspero, poderoso, democrático, civilizado e harmonioso, concretizando o sonho de grande rejuvenescimento da nação chinesa."

Simultaneamente a este vertiginoso dinamismo interno, a China expande sua capacidade de projetar poder econômico, financeiro, político, diplomático, militar e, assim, ocupa posições cada vez mais relevantes no tabuleiro geoeconômico e geopolítico asiático e global. As relações da China com o restante do mundo são redefinidas, o que desencadeia um processo de transição internacional ou uma reconfiguração da ordem mundial. Pequim permanece um ator relevante e busca ampliar sua influência nas instituições internacionais existentes, mas também promove e financia estruturas paralelas: "its own trade deal, its own development bank and its own regional-security grouping" (The Economist, November $15^{\text {th }}, 2014 \mathrm{~b}$ ). O objetivo deste esforço é ampliar sua autonomia para sustentar sua capacidade de defesa interna ante as ameaças estrangeiras e expandir sua esfera de influência para além da Ásia. Assim, participa das organizações internacionais e regimes multilaterais existentes e constrói estruturas suplementares - em parte complementar, em parte competitiva -, procurando reorganizar a ordem internacional, a partir de suas perspectivas e de seus interesses estratégicos (Heilmann et al., 2014, p. 1). Simultaneamente, consolida mudanças estruturais de longo prazo no plano econômico. Primeiro, a ampliação do comércio e do investimento externo chinês com os países em desenvolvimento da Ásia (seu entorno) e do restante do mundo, e inversamente, a redução relativa do comércio com o Japão e com o Ocidente. Segundo, neste movimento de aprofundamento dos vínculos comerciais e de investimento chineses com os países em desenvolvimento, moderniza o conteúdo tecnológico das suas exportações e de suas empresas.

No plano político, no curto prazo, os desafios maiores para os chineses se apresentam no enfrentamento de questões territoriais no Mar do Sul da China (Moraes, 2015). O aumento da insegurança provocada por ações chinesas desde 2009 proporciona a oportunidade para os Estados Unidos reafirmarem sua presença militar e ampliar suas ações no tabuleiro geopolítico asiático: fortalecimento contínuo do Comando Pacífico, seu comando regional mais poderoso, e da Doutrina Obama de contenção da China (a Ásia e a disputa pela hegemonia do Pacífico Sul seriam as prioridades da política externa americana). ${ }^{2}$ Todavia, pelo menos

\footnotetext{
${ }^{2}$ Segundo a Estratégia Nacional de Segurança divulgada pela Casa Branca (The White House, 2015, p.
} 
por ora, os países vizinhos - Vietnã, Filipinas, Malásia, Taiwan e Brunei - não parecem sinalizar que desejam escolher entre os laços econômicos com a China uma vez que lhes proporcionam prosperidade - e a necessidade de segurança, que se inclina no sentido de manter uma presença militar dos Estados Unidos na região. Como a integração econômica asiática se aprofunda - cadeias produtivas regionais e globais - e se torna mais emaranhada, o dilema se metamorfoseia em algo ainda mais complexo dado o crescimento da dependência econômica da região, com relação ao dinamismo chinês. A forma antevista de obter ambos os objetivos seria alcançar um acordo que possibilite relações pacíficas e duradouras entre os Estados Unidos e a China (Kissinger et. al., 2012). Dados os amplos laços de complementariedade entre as duas economias, intimamente interligadas em diversos segmentos produtivos e financeiros (US\$ 3,3 trilhões - no final de dezembro de 2015 - de reservas recicladas pelo sistema financeiro americano), esse acordo não pode ser descartado, a despeito de um acirramento crescente da concorrência entre ambos, seja no âmbito da influência econômica regional, tecnológica e diplomática, seja no âmbito do arsenal militar (Pinto, 2011).

No âmbito da diplomacia, a China está cada vez mais usando fóruns multilaterais e bilaterais para expandir sua influência, especialmente nas relações com países em desenvolvimento. Procura implementar medidas que possibilitem a criação de confiança, seja buscando equacionar conflitos de fronteiras, seja intensificando os laços comerciais, seja realizando investimentos que explicitem um envolvimento pacífico. Uma diplomacia mais ofensiva se ancora na cooperação para o desenvolvimento, sem condicionalidades políticas ou exigências para reformas macroeconômicas, mas com requisitos para exportações de produtos manufaturados chineses ou importações de matérias-primas; na expansão da infraestrutura nacional e conexões regionais; em facilidades de comércio; na realização de elevados montantes de investimentos nos países vizinhos, sobretudo Vietnã, Laos, Camboja, Mianmar, Tailândia e Filipinas. ${ }^{3}$

Nesse novo período de transição internacional, as redefinições das relações da China com o restante do mundo não ficam restritas apenas às questões políticas e diplomáticas, incorporam também as dimensões financeiras, produtivas e de investimentos (megaprojetos).

\footnotetext{
24): “Os Estados Unidos têm sido e continuará a ser uma potência do Pacífico. [...] Os Estados Unidos congratulam-se com a ascensão estável, pacífica e próspera da China. Nós procuramos desenvolver uma relação construtiva com a China que oferece benefícios para os nossos povos e promove segurança e prosperidade na Ásia e em todo o mundo. [...] insistindo que a China respeite as regras internacionais e as normas sobre segurança marítima, comércio e direitos humanos. Vamos monitorar de perto a modernização militar da China e sua presença crescente na Ásia [...]”.

${ }^{3} \mathrm{O}$ caráter proativo da diplomacia chinesa, liderada pelo presidente Xi Jinping, assume a forma de "porretes e incentivos" (sticks and carrots) para "salvaguardar a paz e a estabilidade", sobretudo, no seu entorno. Pequim calcula que pode executar uma política externa regional, simultaneamente, coercitiva e amigável, dado o poder gravitacional exercido por sua economia (Miller, 2014).
} 


\section{A INTERNACIONALIZAÇÃO DO RENMINBI}

As finanças têm se constituído em um instrumento do poder político chinês que as utilizam para impulsionar e proteger sua economia, garantir o suprimento de commodities - agrícolas, minerais e energéticas - e adquirir tecnologias cruciais para seu desenvolvimento econômico e militar. Até meados de 2015, a moeda e o sistema financeiro chinês permaneceram imunes à instabilidade do mercado financeiro internacional. Todavia, delineou-se um movimento de ampliação do uso de sua moeda - o renminbi $(\mathrm{RMB})^{4}$ - em operações de comércio e de investimento externo, com repercussões sobre o mercado financeiro por meio doméstico e global. Segundo a plataforma de pagamento global, Sociedade para Telecomunicações Financeiras Interbancárias Mundiais (Society for Worldwide Interbank Financial Telecommunication - SWIFT), o renminbi se tornou a quinta moeda mais utilizada em dezembro de 2014. A moeda chinesa respondeu por $2,17 \%$ das operações de pagamento internacionais; antecedida pelo iene japonês, que foi usado em 2,69\% das transações; pela libra esterlina, em 7,92\%; pelo euro, em $28,30 \%$; e pelo dólar, em 44,64\% (Noble, 2015). ${ }^{5}$ Também, de acordo com a plataforma SWIFT: "50 países estavam usando a moeda [chinesa] em mais de $10 \%$ de seus pagamentos com a China e Hong Kong no final de outubro de 2014” (SWIFT, 2014). Entre outras ações de cooperação financeira em favor da internacionalização do renminbi, destacam-se:

i. tratados de compensação de operações internacionais de renminbi com catorze centros financeiros (Hong Kong, Macau, Taiwan, Cingapura, Londres, Frankfurt, Seul, Paris, Luxemburgo, Doha, Toronto, Sydney, Kuala Lumpur e Bangkok);

ii. autorização de nove cotas específicas de Investidor Institucional Estrangeiro Qualificado em RMB (RMB Qualified Foreign Institutional Investor-RQFII), que permite investidores institucionais estrangeiros utilizar os fundos offshore de renminbi para investir no mercado de capitais chinês e no mercado interbancário de títulos;

iii. acordos de swap de moedas com 30 bancos centrais;

iv. atuação com emprestador de última instância para países com dificuldade de acesso ao mercado financeiro internacional - Venezuela e Equador (Global Risk Insights, 2015; Ostroukh, 2015); e

v. um sistema de pagamento independente para as operações em renminbi

\footnotetext{
${ }^{4}$ RMB é a abreviação da moeda chinesa renminbi - "moeda do povo" -, cuja unidade básica é o iuane. CNY é o código monetário oficial da moeda chinesa negociada no mercado nacional, lançada em 1949 pela República Popular da China. Em 2009, começou a funcionar um mercado de renminbi em Hong Kong, com o código monetário $\mathrm{CNH}$.

${ }^{5}$ Para mais detalhes sobre as políticas de internacionalização do renmimbi ver BIS (2013), Cintra e Martins (2013), Cohen (2012).
} 
- China International Payment System (CIPS) - uma alternativa à plataforma SWIFT.

Ademais, procurou-se transformar a praça financeira de Xangai em um centro financeiro global. Além do mercado de ações (Shanghai Stock Exchange), já operavam mercados futuros (Shanghai's Futures Exchange) de petróleo, gás natural e produtos petroquímicos, uma plataforma de negociação de ouro, prata e cobre e, no final de 2014, começou a ser implementada a conexão entre a Bolsa de Valores de Xangai e a de Hong Kong (cross-border share trading scheme), como mais uma etapa da abertura da conta de capital e internacionalização da moeda chinesa. Buscou-se consolidar também um sistema de pagamento nacional e internacional - $\mathrm{o}$ cartão de crédito e débito bancário UnionPay - aceito 141 países (inclusive no Brasil, dada a associação com o Banco Itaú) e emitido em 30 países (Ninio, 2015). A partir de junho de 2013, começou a operar uma agência de classificação de risco de crédito - Universal Credit Rating Group -, projeto desenvolvido por três agências de rating (Dagong Global Credit, RusRating e Egan-Jones Rating), sediada em Hong Kong, com o objetivo de solidificar um sistema de classificação de risco asiático.

Os países-membros dos BRICS (Brasil, Rússia, Índia, China e África do Sul) negociaram um Arranjo Contingente de Reserva, no valor de US\$ 100 bilhões, sendo que a China contribuiu com US\$ 41 bilhões; Brasil, Rússia e Índia, com US\$ 18 bilhões cada um; África do Sul, com US\$ 5 bilhões. Acordo similar à Iniciativa Chiang Mai de troca de moedas entre os países asiáticos (ASEAN+3) no montante de US\$ 240 bilhões - a contribuição da China equivale a 32\% do total, mesma do Japão, acompanhada de $16 \%$ da Coreia do Sul, os países da ASEAN responderam pelos $20 \%$ restantes. Ambas as iniciativas preveem dispositivos que regulamentam o acesso aos recursos pelos demandantes: até determinada quantia, o acesso é livre, bastando haver a solicitação; acima deste valor, torna-se necessário algum tipo de garantia - um acordo com o FMI.

Não se pode deixar de mencionar a criação do Novo Banco de Desenvolvimento BRICS, com sede em Xangai e capital total de US\$ 100 bilhões, subscritos inicialmente US\$ 50 bilhões, de forma paritária entre os cinco sócios, em julho de 2014. Terá foco no financiamento da infraestrutura (estradas, eletricidade e ferrovias etc.) dos países em desenvolvimento. ${ }^{6} \mathrm{E}$, em outubro do mesmo ano, ocorreu o lançamento do Banco Asiático de Investimento em Infraestrutura (Asian Infrastructure Investment Bank), um banco intergovernamental com sede em Pequim e capital de US\$ 100 bilhões, dos quais US\$29,8 bilhões subscritos pela China, US\$ 8,4 bilhões pela Índia, US\$ 6,5 bilhões pela Rússia. Com 57 países-membros, terá como objetivo financiar projetos de infraestrutura na região. Essas novas instituições multilaterais de crédito - as primeiras no campo financeiro internacional que escapam aos desígnios das finanças pública e privada anglo-americana, mesmo sem confrontá-los - ampliam o poder financeiro chinês (ancorado no superávit em

\footnotetext{
${ }^{6}$ Para outras informações, ver Griffith-Jones (2014), Griffith-Jones, Fritz e Cintra (2014) e Carvalho et al., (2015).
} 
conta-corrente que somou US\$ 293 bilhões em 2015), permitindo, por exemplo, o estabelecimento de novas prioridades, princípios e procedimentos para assistência ao desenvolvimento nacional, regional e multilateral.

Outro elemento desse processo tem sido a transformação de um histórico centro financeiro internacional, Hong Kong, para projetar o seu poder monetário e financeiro ao restante do mundo. Como a moeda chinesa não é plenamente conversível, o governo utilizou Hong Kong - com a criação de um mercado offshore de renminbi para não residentes - a fim de permitir que bancos, corporações e investidores institucionais estrangeiros detenham depósitos, tomem empréstimos (comerciais e emissão de bônus) e liquidem transações comerciais em renminbi, sobretudo entre os países do entorno asiático. $\mathrm{O}$ incipiente mercado de renminbi em Hong Kong $(\mathrm{CNH})$, no entanto, persistiu sujeito a uma variação considerável da liquidez, apresentando elevada volatilidade. A demanda por renminbi e por ativos denominados em renminbi permaneceu comandada pelo desempenho da economia chinesa e pelas expectativas de valorização da moeda.

A conversibilidade do renminbi pressupõe o aprofundamento do mercado doméstico de títulos de dívida, a capacidade de grandes investidores institucionais nacionais gerirem a poupança das famílias em carteiras diversificadas de ativos, a acomodação de investidores estrangeiros nos mercados de ativos financeiros domésticos em condições de riscos gerenciáveis. Poderá pressupor também a vontade política dos países do Leste Asiático de lançar uma iniciativa mais ambiciosa do que a Chiang Mai e criar uma área de cooperação monetária que apoie a internacionalização das moedas nacionais da região. Uma internacionalização das moedas e uma cooperação regional a fim de preservar a paridade das taxas de câmbio cruzadas (cross-exchange rates) reduziria substancialmente a possibilidade de desvalorizações competitivas, facilitaria a integração dos países vizinhos em sua economia doméstica e promoveria a disseminação do renminbi pela região mais dinâmica do mundo (Aglietta e Bai, 2012, p. 211).

Fiel ao método gradualista, o governo vem aprofundando as conexões do sistema financeiro doméstico com o internacional passo a passo, com mudanças incrementais - graduais e cumulativas. Hong Kong e Xangai se transformam em áreas de experimentação sobre os impactos da progressiva liberalização do renminbi e da abertura da conta de capital. Simultaneamente, fortalece a posição do banco central que busca acelerar a reforma do sistema financeiro doméstico, sobretudo a precificação dos instrumentos financeiros e a gestão de riscos, uma vez que as instituições chinesas seriam confrontadas por práticas internacionais, podendo mudar seu comportamento, tornando-as mais competitivas. Assim, as reformas dos mercados financeiros nacionais e a abertura da conta de capital são mudanças estruturais das finanças chinesas, que procuram adaptá-las para a nova fase econômica do país e do mundo.

Pequim procura, então, promover a "internacionalização controlada" do renminbi, nas trocas comerciais e nas finanças, buscando se adequar ao aprofundamento da globalização financeira e produtiva e reduzir as assimetrias do sistema monetário internacional, que condicionam as potencialidades e os graus de liber- 
dade das políticas domésticas e externas. De forma inédita, o que torna o processo mais difícil e pouco previsível, busca internacionalizar o renminbi com controles sobre a conta de capital. Vale dizer, restringindo a plena conversibilidade da moeda ou construindo uma conversibilidade limitada. ${ }^{7}$ Isso passa, por ora, pela articulação de um mercado offshore de renminbi em Hong Kong, tornando-o atraente para os investidores residentes e estrangeiros, além de um conjunto de incentivos e de mecanismos de persuasão para fomentar o uso internacional do renminbi, sobretudo no âmbito das transações comerciais, dado que seu comércio continuará a crescer, e as empresas chinesas estimularão os clientes a liquidar suas transações em renminbi.

Em 2015, o presidente do banco central indicou um conjunto de políticas para acelerar a liberalização da conta de capital: revisar a regulamentação sobre o mercado de câmbio, ampliar a participação de investidores estrangeiros no mercado de bônus, permitir aos investidores individuais, na China e no exterior, efetuar operações transfronteiras, flexibilizar a definição das taxas de juros domésticas e viabilizar um sistema de seguro de depósitos bancários. Estas decisões estavam relacionadas com a estratégia de qualificação do renminbi para ser incluído na cesta de moedas que compõe os Direitos Especiais de Saque (Special Drawing Rights - SDR) - um ativo de reserva cambial complementar mantido pelo FMI. A inclusão representou um reconhecimento simbólico de que o renminbi seria verdadeiramente uma moeda-reserva internacional (Zhang e Shi, 2015, p. 2; Long, 2015a, p. 7). ${ }^{8}$

Dessa forma, o governo chinês tem se mostrado determinado a expandir o uso do remminbi no exterior, enquanto flexibiliza o mercado de câmbio doméstico. A partir de abril de 2014, o Banco Central da China passou a orquestrar uma banda diária de flutuação de $2 \%$ para cima e para baixo, com a preocupação de evitar desvalorizações acentuadas do renminbi, pois “China's regional and global geos-

\footnotetext{
${ }^{7}$ O FMI denominou o processo de "conversibilidade administrada" ("managed convertibility”), uma vez que busca: i) combinar um sistema de monitoramento dos investimentos diretos com licenças e autorizações para transações de títulos e de empréstimos (sendo o objetivo mudar todos os procedimentos de autorizações para monitoramento); ii) monitorar as transações em tempo real, quanto possível, e tomar medidas, se necessário, para conter fluxos potencialmente desestabilizadores (medidas macroprudenciais e sobre os fluxos de capitais); iii) manter limites sobre as posições estrangeiras e sobre a dívida externa de curto prazo (microprudencial); $i v$ ) exercer supervisão rigorosa sobre lavagem de dinheiro, financiamento ao terrorismo e evasão fiscal (IMF, 2015a, p. 52).

Eichengreen e Kawai (2015, p. 12), por sua vez, caracterizaram a estratégia de conversibilidade "básica" (não plena) da conta de capital. Vale dizer, o renminbi progredirá como moeda de denominação e liquidação das trocas comerciais, como veículo para entrada e saída de investimento direto e, talvez, para emissão de bônus internacionais. Porém, a liberalização limitada dificultará que os bancos internacionais utilizem o renminbi para gestão de liquidez, que os investidores institucionais globais incluam ativos em renminbi em suas carteiras, que as multinacionais o incorporem em seus programas de gestão de moedas, e que os bancos centrais o mantenham entre os relevantes ativos de reservas.

${ }^{8} \mathrm{Na}$ revisão das moedas componentes dos Direitos Especiais de Saque em 2010 definiu-se: dólar $(41,9 \%)$, euro $(37,4 \%)$, libra esterlina $(11,3 \%)$ e o iene $(9,4 \%)$. Em dezembro de 2015 , o FMI anunciou a seguinte recomposição: dólar $(41,73 \%)$, euro $(30,93 \%)$, renminbi $(10,92 \%)$; iene $(8,33 \%)$ e libra esterlina (8,09\%), a partir de 1을 de outubro de 2016 (IMF, 2015b).
} 
trategic goals require it to maintain a strong currency" (Long, 2015a, p. 1), estável e que opere como âncora para as moedas regionais.

Em 11 de agosto de 2015, a autoridade monetária desvalorizou o renminbi em $1,9 \%$ e sinalizou com uma política mais flexível, uma vez que a cotação passaria a se alinhar com as taxas de fechamento do dia anterior no mercado à vista. Ou seja, a taxa de câmbio refletiria as expectativas dos negociadores (dealers), entre 10-20, incluindo bancos domésticos e estrangeiros. As autoridades deixaram claro, porém, que a maior flexibilidade não implicaria ausência de intervenção. E, face dos impactos desencadeados pela medida, a necessidade de intervenção se fez sentir de forma recorrente e em grandes volumes. Nos dias seguintes, a venda de dólares e a compra de renminbi foi estimada entre US\$ 90 bilhões e US\$ 140 bilhões, para conter uma desvalorização abrupta. Foi necessária ainda a injeção de elevados montantes de recursos no sistema financeiro doméstico para contrabalançar a contração da liquidez (Simoens, 2015, p. 76).

Diante de um maior grau de abertura financeira, as incertezas sobre a desvalorização da moeda resultaram em um déficit na conta de capital de US\$ 504 bilhões que, acrescido dos US\$ 132 bilhões em “erros e omissões”, somou US\$ 636 bilhões, a despeito de um superávit na balança comercial de US\$ 595 bilhões e na conta-corrente de US\$ 293 bilhões, segundo dados preliminares do balanço de pagamento de 2015. Com isso, as reservas internacionais caíram US\$ 343 bilhões. Uma parte significativa desse movimento esteve associada ao pagamento da dívida externa pelas empresas chinesas. No período anterior, elas haviam acumulado dívida em moeda estrangeira (normalmente dólar), aproveitando as vantagens das baixas taxas de juros offshore e da apreciação do renminbi. Outra proporção proveio do aumento de investimento direto das empresas chinesas no exterior e da queda nas operações financeiras intercompanhias das multinacionais, seja reduzindo dívidas, seja desmontando posições especulativas, o que resultou em uma contração do investimento estrangeiro direto líquido. Assim, as saídas de capital líquidas podem ser classificadas da seguinte forma: 30\% referente ao pagamento de dívida externa, $30 \%$ aos investimentos das empresas chinesas no exterior, $10 \%$ ao aumento de depósitos estrangeiros (exportadores retendo suas receitas em dólar para reduzir possíveis perdas com a desvalorização do renminbi e diminuir as exposições em moeda estrangeira) e 30\% a "erros e omissões" (Long, 2016, p. 5). Enfim, há poucos indícios de que as empresas e as famílias estejam trocando renminbi por dólares em larga escala (exceto pelo volume de "erros e omissões" no balanço de pagamentos).

Ademais, as identidades básicas do balanço de pagamentos informam que países com superávits na conta-corrente tendem a apresentar déficits na conta de capital, tornando-se credores líquidos do resto do mundo. Todavia, quando a saída de capital excede o montante que entra pela conta-corrente, a taxa de câmbio tende a se ajustar (ou seja, desvalorizar). Alternativamente, o banco central pode utilizar as reservas internacionais para compensar a saída de capital e manter a taxa de câmbio estável. Esse tem sido o desafio e o aprendizado da China, o déficit na conta capital foi maior do que o superávit na conta-corrente, criando pressões 
para um ajuste na taxa de câmbio, contidas pelas intervenções do banco central. O estoque de reservas - US \$3,33 trilhões - continua elevado, permitindo que o banco central persista na defesa da moeda. Porém, a estratégia não parece sustentável porque a estabilidade da taxa de câmbio somente pode ser alcançada quando o banco central intervém, vale dizer, gasta reservas (Long, 2016, p. 6). Dessa forma, o regime de câmbio tornou-se dependente das intervenções - venda de moeda estrangeira pelo Banco Central da China.

Assim, parece que a China não enfrenta propriamente um problema de saída de capital, mas de regime de câmbio, que perdeu credibilidade em uma economia mais integrada ao sistema financeiro global, cuja variável preponderante é a política monetária americana. ${ }^{9}$ As saídas de capital têm sido suficientes para desencadear declínio nas reservas, que gradualmente reduz a capacidade de o banco central impedir a desvalorização da moeda doméstica. As expectativas dos agentes acerca de uma moeda mais desvalorizada são reforçadas, que produzem mais saídas de capital. O círculo vicioso somente será interrompido quando as reservas internacionais deixarem de cair (Long, 2016, p. 5). Nesse contexto, quais seriam as alternativas: i) deixar a moeda flutuar, o que desencadearia uma desvalorização de $15 \%-20 \%$ antes de se estabilizar em um novo patamar, provocando uma grande instabilidade nos mercados financeiros globais; ii) reforçar os instrumentos existentes de controles sobre os fluxos de capitais. Há sinais nesta direção, tais como restrições impostas às compras internacionais realizadas pelo cartão de crédito Union Pay e às promoções das gestoras de ativos domésticas de investimentos no mercado acionário externo, e maior escrutínio sobre as transferências de indivíduos; iii) reduzir as saídas líquidas de capitais e as reservas pararem de cair, seja porque as empresas chinesas diminuíssem os pagamentos de suas dívidas externas e/ou os investimentos diretos no exterior, seja porque o Federal Reserve alterasse o curso de sua política monetária. Se o Federal Reserve adiasse o aumento da taxa de juros básica reverteria a direção dos fluxos de capitais globais e desencadearia uma expectativa de desvalorização do dólar (Long, 2016, p. 6-7). Tal reversão permitiria que o Banco Central da China mantivesse a taxa de câmbio ancorada em uma cesta de moedas (basket peg) por mais algum tempo. Como afirma Aglietta (2015):

"Que essas inovações institucionais [liberalização do mercado de câmbio] criem perturbações financeiras não é algo que deva surpreender. Todos os países que liberalizaram abruptamente seus sistemas financeiros passaram por crises financeiras mais ou menos intensas e extensas [...]. Esses redemoinhos acalmam-se quando os governos adaptam sua regulamentação prudencial e quando o banco central ajusta os instrumentos

\footnotetext{
${ }^{9}$ Salienta-se que a atuação do sistema bancário chinês persiste predominantemente interna, o que limita a capacidade de expansão e de defesa das transações em renminbi em âmbito global, ficando sujeito a processos especulativos dos investidores internacionais (refletidos nos diferenciais de taxas de juros e de câmbio nos mercados onshore e offshore). Para as especificidades do sistema financeiro chinês, ver Cintra e Silva Filho (2015).
} 
de ação de sua política monetária [e cambial]. É isso que as autoridades chinesas tentam fazer agora."

A China aponta, portanto, com a aceleração da liberalização da conta de capital, o que impõe desafios formidáveis, pois requer modificações em seu arcabouço macroeconômico cujos pilares centrais têm sido taxa de câmbio, taxas de juros, empréstimos bancários e mercado para a dívida pública administrados. No âmbito da tradição chinesa de mudanças graduais e controladas, o governo provavelmente avaliou que os riscos seriam manejáveis por meio de medidas macro e microprudenciais e os benefícios superariam os riscos. De todo modo, o mais provável é que o governo chinês continue cauteloso, evitando uma completa e abrupta liberalização financeira. Afinal, esse movimento em direção à globalização financeira - vale dizer, à entrada na gestão da moeda, do crédito e da riqueza financeira em âmbito internacional - pode desencadear repercussões monetário-financeiras em que as "mudanças graduais e controladas" não sejam um antídoto duradouro. A experiência internacional mostra que a liberalização dos fluxos de capitais aumenta a volatilidade da taxa de câmbio e de juros e, por conseguinte, do produto, reduzindo os raios de manobra para a definição das políticas domésticas, uma vez que os países ficam sujeitos a ondas de entrada e saída de recursos. Muitas economias desenvolvidas e em desenvolvimento experimentaram crises financeiras e cambiais após a liberalização da conta de capital.

Em âmbito mais geral, sobre a meta de o governo chinês alcançar o status de moeda-reserva para o renminbi, Kroeber (2012b, p. 14) explicita o âmago da questão, distinguindo três dimensões do sistema monetário internacional: uma moeda internacional, uma moeda-reserva (detida pelos bancos centrais em ativos líquidos, seguros e de baixo risco) e a principal moeda-reserva mundial. O renminbi está se internacionalizando celeremente e uma parte significativa do comércio chinês será liquidada em renminbi. A inclusão na cesta de moedas que compõe os Direitos Especiais de Saque permitirá que os bancos centrais aloquem uma pequena parte das suas reservas internacionais em renminbi, tornando-a uma moeda-reserva secundária, semelhante à libra esterlina ou ao iene. É muito pouco provável, no entanto, que o renminbi esteja perto de alcançar o status de uma importante moeda-reserva global (como o dólar). E há zero de possibilidade que o renminbi substitua o dólar como principal moeda-reserva do mundo nas próximas décadas. Nas palavras de Eichengreen e Kawai $(2015$, p. 3): "the RMB is more likely to develop into a regional than a global currency".

Enfim, a internacionalização do renminbi decorre da emergência da China como uma potência econômica e comercial (não como potência financeira). Pelo menos, no horizonte visível, sua expansão ocorrerá no âmbito do sistema monetário global dominado pelo dólar flexível. É justamente essa dependência que leva Pequim a promover a internacionalização do renminbi: quanto mais empresas conseguirem liquidar suas importações e exportações, e seus investimentos no exterior (sobretudo na Ásia) em renminbi, menos o Banco Central da China necessitará efetuar depósitos no sistema financeiro americano. 


\section{INTERNACIONALIZAÇÃO DO CAPITAL: ENTORNO ASIÁTICO E MEGAPROJETOS DE INVESTIMENTOS}

A internacionalização do capital chinês por meio do investimento direto estrangeiro (IDE), sobretudo após a crise de 2008, constituiu um dos fenômenos empresariais mais profundos das últimas décadas. O país se tornou um dos maiores investidores do mundo, sendo boa parte deste investimento realizada no entorno asiático em construção de estradas, barragens, redes de energia elétrica e em segmentos do setor manufatureiro.

A internacionalização chinesa teve sua origem no programa governamental “Going Global”, estabelecido pelo $16^{\circ}$ Congresso do Partido Comunista em 1999, que delineava quatro grandes objetivos: $i$ ) aumentar o investimento direto chinês no exterior por meio da descentralização e relaxamento das autorizações para saída das corporações; ii) melhorar o nível e a qualidade dos projetos; iii) reduzir os controles de capital e criar novos canais de financiamento; e iv) integrar a política de internacionalização das companhias chinesas com outras políticas existentes para o setor externo, buscando promover o reconhecimento das marcas dessas empresas (Acioly, Pinto e Cintra, 2011; Deng, 2013).

É preciso observar que a internacionalização da China foi e é fortemente comandada por seu Estado que buscou fortalecer suas estratégias de desenvolvimento. ${ }^{10}$ Este passou a incentivar as empresas locais por meio de mecanismos de financiamentos, de facilitação do processo administrativo para a realização de investimentos diretos no exterior e de construção ou financiamento de megaprojetos de integração física (rodovias, ferrovias, portos, telecomunicações etc.) em outras regiões (Eurásia, América Latina, África etc.) e também com seus vizinhos, sobretudo na sub-região do Grande Mekong. Com isso, procurou abrir novos corredores econômicos voltados à ampliação dos investimentos e do comércio regional para os produtos e empresas chinesas (Ueki, 2010; Deng, 2013; Vu, 2014).

Não se pode deixar de salientar também que esta intensificação mais recente dos investimentos no exterior - tanto em infraestrutura como na implantação de novas empresas multinacionais industriais - se articula com a necessidade de se sustentar a demanda pela produção doméstica excedente em diversos setores, tais como máquinas e equipamentos de construção, siderurgia, cimento, alumínio, energia solar etc. (Scherer, 2015). No curto prazo, constitui-se um movimento de exportação de investimentos com o objetivo de garantir demanda para a capacidade produtiva ociosa disponível na indústria pesada.

\footnotetext{
${ }^{10}$ As principais medidas de políticas de apoio a internacionalização das empresas adotadas na China foram: incentivos financeiros e fiscais, apoio informacional, assistência técnica e outros serviços, criação de confort zones, e acordos internacionais. A existência de estratégia de expansão produtiva em função dos objetivos da política industrial do país e da sustentabilidade do balanço de pagamentos controlou o ritmo e a direção do IDE e condicionou o grau de intervenção do Estado. À medida que a restrição externa foi sendo aliviada pelo acúmulo de reservas, a política de saída de IDE foi sendo flexibilizada (Acioly, Pinto e Cintra, 2011).
} 
Como resultado dessa estratégia, o estoque de IDE da China no exterior chegou a US\$ 730 bilhões em 2014, cerca 26 vezes mais que o valor de US\$27,8 bilhões registrado em 2000 (The Economist, 2010; Deng, 2013; Unctad, 2014). A participação do investimento chinês no estoque mundial de IDE alcançou o patamar de 2,8\% em 2014 (Gráfico 1).

Gráfico 1: China: estoque de IDE no mundo 2000-2014 (US\$ bilhões)

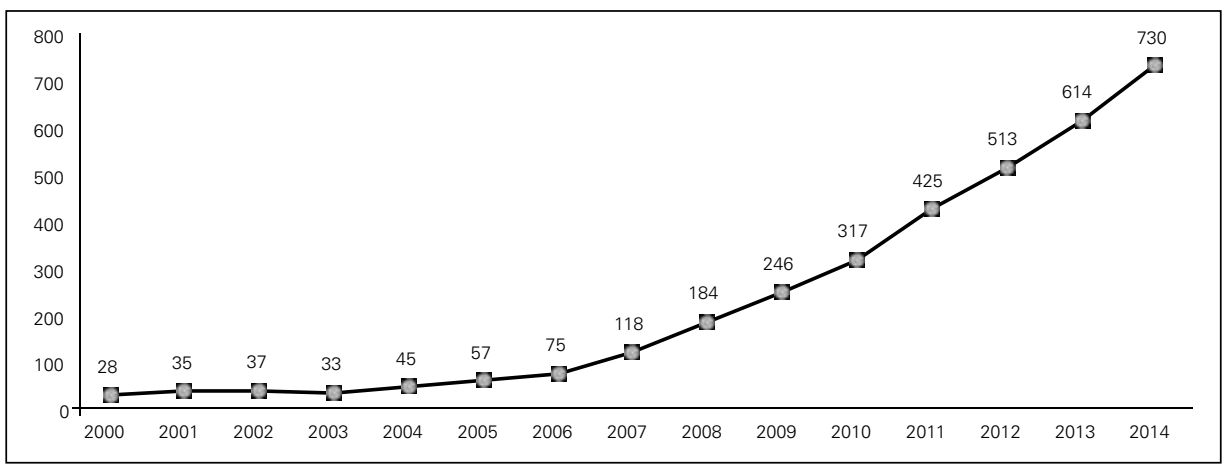

Fonte: Unctad.

Observa-se que a expansão do IDE chinês ocorreu mesmo quando existia forte potencial de expansão no mercado interno. Nesse sentido, Acioly, Pinto e Cintra (2011) e Deng (2013) apontaram os quatro principais eixos explicativos desse processo: i) garantir acesso às fontes de recursos naturais por meio de uma política agressiva de investimentos externos liderados por grandes empresas estatais; ii) buscar maior competitividade para as firmas chinesas; iii) obter maior tecnologia para as corporações chinesas por meio de aquisição de empresas estrangeiras, notadamente na Europa e nos Estados Unidos; iv) garantir demanda no curto prazo para a capacidade produtiva ociosa da indústria pesada chinesa; e $v$ ) aumentar a influência política da China no mundo, sobretudo na Ásia e seu entorno, por meio da realização dos investimentos, com destaque para os megaprojetos de infraestrutura.

O eixo articulador desta estratégia de internacionalização do capital chinês tem sido a realização de megaprojetos de infraestrutura transnacional, por meio de uma ambiciosa "diplomacia da infraestrutura" (Kroeber, 2015a, p. 3; The Economist, 2015). Estima-se que as empresas chinesas - incluindo Hong Kong - investirão no exterior US\$1,25 trilhão durante a próxima década. Em dezembro de 2014, uma empreiteira privada de Hong Kong em colaboração com as companhias estatais chinesas desencadearam a construção do Canal Interoceânico da Nicarágua, estimado em US\$ 50 bilhões, com $278 \mathrm{~km}$ de extensão, maior e mais complexo do que o Canal do Panamá. O presidente Xi Jinping, em novembro de 2013, anunciou a "obra do século 21" denominado o Cinturão Econômico da Rota da Seda (Silk Road Economic Belt), que objetiva estabelecer uma infraestrutura de grande escala - uma malha ampliada de trens de alta velocidade, estradas, redes elétricas, cabos de fibra óptica e sistemas de telecomunicações, oleodutos, gasodutos etc. - para 
abrir novos corredores comerciais por terra e por mar - Rota da Seda Marítima (Maritime Silk Road) - por toda a Eurásia. Trata-se de articular, sobretudo, três cinturões (rodoviário, ferroviário e marítimo) que ligarão a China à Europa, passando por 21 países (ampliando as conexões com as economias do Leste da Ásia, Sul da Ásia, Ásia Central e Golfo Pérsico). ${ }^{11}$ Os portos construídos no Leste da Ásia e Oceano Índico (Bangladesch, Sri Lanka, Birmânia e Paquistão) serviriam para impulsionar o comércio por mar. Constitui, portanto, iniciativas que alavancam o papel do país no comércio e nas finanças mundiais - "all this region's trade routes will lead to Beijing" (Power, 2015) -, articulando um novo Plano Marshall, que viabilizou a recuperação das economias europeias após a Segunda Guerra Mundial, agora, envolvendo 3 bilhões de habitantes espalhados por dezenas de países.

Além desses dois projetos (Canal Interoceânico da Nicarágua e "Um Cinturão, Uma Estrada" - One Belt, One Road), outros quatros megaprojetos estão em andamento ou concluídos. Primeiro, uma nova autoestrada, estimada em US\$ 4 bilhões, ligará Kunming, capital da Província de Yunnan, à capital da Tailândia, Bangkok, passando pela província de Luang Namtha, norte do Laos, pelo estado de Shane em Mianmar e por Hanói no Vietnã (Vu, 2014). A Província de Yunnan é percebida como "ponta de lança" para reforçar a influência do país na bacia do Grande Mekong, onde as empresas chinesas constroem estradas, barragens, redes de energia elétrica; investem em minas, imóveis e agricultura. O programa de desenvolvimento do Grande Mekong é apoiado pelo Banco Asiático de Desenvolvimento (ADB) e a China aloca o maior volume de recursos, com o objetivo de promover o desenvolvimento e a integração regional dos países que compõem essa sub-região (China, províncias de Yunnan e Guangxi, Mianmar, Laos, Tailândia, Camboja e Vietnã) por meio da redução dos obstáculos físicos (construção de corredores econômicos) ao comércio e ao investimento. Segundo, o corredor econômico China-Mianmar-Bangladesh-Índia composto por uma autoestrada e outras infraestruturas que ligarão Kunming e Calcutá, na Índia. Terceiro, um oleoduto e um gasoduto já ligam Kunming a Kyaukphyu, no litoral de Mianmar (Baía de Bengala), permitindo alargar sua esfera de influência para o Oceano Índico. Quarto, o corredor econômico China-Paquistão, que obteve uma linha de crédito de US\$ 46 bilhões para projetos de infraestrutura - energia, rodovias, ferrovias e modernização do porto de Gwadar - em abril de 2015 (Miller, 2015).

Essa internacionalização do capital chinês, centrada nos megaprojetos de investimentos, vem ampliando a integração regional asiática e criando um emaranha-

\footnotetext{
${ }^{11}$ Em 15 de dezembro de 2014 foi dado, em Istambul, na Turquia, o primeiro passo da "obra do século 21”. A construção da infraestrutura será apoiada por um Fundo da Rota da Seda de US\$ 40 bilhões patrocinados pela China; o restante dos investimentos será financiado Banco Asiático de Investimento em Infraestrutura e pelos bancos desenvolvimento chineses (sobretudo China Development Bank e China Export-Import Bank). Ver o documento - Vision and actions on jointly building Silk Road Economic Belt and 21st-Century Maritime Silk Road - divulgado pela Comissão Nacional de Desenvolvimento e Reforma, Ministério das Relações Exteriores e Ministério do Comércio com a autorização do Conselho de Estado em março de 2015.
} 
do de interesses que cada vez mais depende do dinamismo econômico chinês e da configuração de novas instituições multilaterais de crédito. Nesse sentido, o Banco Asiático de Investimento em Infraestrutura, criado para financiar a infraestrutura regional, deverá assumir um papel central. Esse banco intergovernamental tem o papel de dissipar os temores dos países fronteiriços de uma excessiva dependência financeira da China. Os projetos financiados pelas instituições de desenvolvimento plurilaterais ampliam a confiança nos contratos celebrados pelas empresas chinesas mais do que as operações de empréstimos bilaterais. $\mathrm{O}$ financiamento de projetos de infraestrutura por meio do novo banco dotará a integração asiática de novo impulso e a China gozará de acesso privilegiado a recursos naturais estratégicos além de potenciais mercados consumidores. ${ }^{12}$

Em linhas gerais, pode-se afirmar que Pequim delineia claramente uma racionalidade por trás destes megaprojetos de infraestrutura que pode ser estruturada a partir de seis pontos. O primeiro diz respeito ao aprofundamento da integração física com os países fronteiriços, relativamente subdesenvolvidos, que pode viabilizar novas redes de comércio, abrir novas rotas de trânsito para suas exportações de bens e serviços, fomentar o desenvolvimento desses países e, simultaneamente, auxiliar na contenção dos conflitos étnicos na região instável de Xinjiang. O segundo ponto é possibilitar que os países vizinhos se beneficiem de sua ascensão reforçando a diplomacia "ganha-ganha". Isso marca uma mudança com o passado recente, quando Pequim cultivava estreitas relações diplomáticas apenas com Coreia do Norte e Mianmar. O terceiro ponto refere-se ao financiamento e à construção de infraestrutura em regiões fronteiriças relativamente subdesenvolvidas da Ásia procurando conquistar a confiança dos países vizinhos no projeto de prosperidade recíproca e de destino comum, tornando sua ascensão mais aceitável. Caso contrário, corre o risco de criar uma coalizão liderada pelos Estados Unidos que buscará restringir suas ambições (Miller, 2014). O quarto ponto dessa racionalidade centra-se nos efeitos da configuração da Rota da Seda Marítima sobre o comércio e o plano militar. A China está construindo uma forte Marinha para proteger suas rotas de abastecimento independentemente da Marinha americana. O objetivo de longo prazo é exercer controle sobre os Mares da China e empurrar a Marinha americana para o Pacífico Ocidental. O quinto diz respeito ao financiamento de megaprojetos de infraestrutura que, mesmo com relativamente baixas taxas de retorno, constitui uma forma mais atraente de aplicar as reservas internacionais do que mantê-las em títulos do governo americano com baixíssimas taxas de juros. Por fim, o sexto ponto está atrelado à construção de infraestrutura ao longo das fronteiras e à modernização dos portos na Ásia que representa a tentativa de restauração da posição da civilização chinesa, projetando as bases de um império econômico (Miller, 2014).

\footnotetext{
${ }^{12}$ O Banco de Desenvolvimento da Ásia estimou que a escassez de financiamento para infraestrutura na região - incluindo a China - montaria a US\$ 8 trilhões, durante a década de 2010-2020. Indicações mais realistas para as necessidades de infraestrutura fora da China, em torno dos projetos potenciais do “Um Cinturão, Uma Estrada” (One Belt, One Road), sinalizam US\$ 890 bilhões, segundo o China Development Bank (Kroeber, 2015b, p. 35).
} 


\section{CONCLUSÃO}

Após uma década em que a China se expandiu vertiginosamente e ocupou posições cada vez mais importantes no tabuleiro geoeconômico e geopolítico asiático e global, o "sistema interestatal capitalista" atravessa uma transformação tectônica. Neste movimento, parece cada vez mais claro que a China planeja forjar uma nova fase da globalização em que suas empresas se tornam globais, sejam capazes de definir os padrões mundiais e de condicionar a dinâmica da economia internacional. Enquanto se torna parceiro comercial predominante de muitos países, amplia seus investimentos no exterior, expande seu poder econômico, que ancora a formatação das regras e das instituições internacionais.

Dessa forma, há sinais de transbordamento do capital monetário e bancário chinês para além de suas fronteiras. A moeda e as finanças vão ocupando novas posições no cenário mundial, dada a política de internacionalização do renminbi, da praça financeira de Xangai, de um mercado offshore em Hong Kong, de expansão das operações de empréstimos dos grandes bancos estatais, que financiam projetos de infraestrutura e investimentos das corporações chinesas nos países em desenvolvimento, impulsionando suas taxas de crescimento, o aumento do comércio bilateral que aprofunda os laços com o Império do Meio. A moeda chinesa persiste, no entanto, com uma conversibilidade limitada, consolidando-se na liquidação das trocas comerciais e nas transações de investimentos, sobretudo, em âmbito regional. Mas dificilmente se tornará, no horizonte visível, uma moeda-reserva relevante no sistema monetário global dominado pelo dólar flexível.

O objetivo estratégico de longo prazo está claro: restaurar a posição histórica da China na Ásia. Como afirmou o presidente Xi Jinping: "Isto é para o povo da Ásia ... para defender a segurança da Ásia" (The Economist, November 15 ${ }^{\text {th }}, 2014 \mathrm{~b}$ ). A China emite, portanto, sinais de irradiar sua grandeza para além dos seus próprios limites territoriais, redefinindo suas relações com o restante do mundo e, por conseguinte - dado seu poder econômico, financeiro, político, diplomático, militar -, desencadeando um processo de reconfiguração da ordem mundial.

Evidentemente, tal processo não ocorre sem fricções nem sem reações. Os Estados Unidos, por exemplo, negociam a Parceria Transpacífica (TPP), um acordo comercial entre 12 países do Pacífico, que exclui a China. Em entrevista ao The Wall Street Journal, o presidente Barack Obama afirmou: "Se nós não escrevermos as regras, a China escreverá as regras para aquela região. [...] Nós seremos excluídos - as empresas americanas e a agricultura americana. E isso significará perda de empregos nos Estados Unidos" (Seib, 2015). Este novo cenário econômico pode fortalecer o dólar, como moeda de pagamentos e de reserva internacional, em razão das vantagens competitivas detidas pelos Estados Unidos, recolocando desafios gigantescos aos países em desenvolvimento. A China reage ao propor a Parceria Econômica Regional Abrangente, mas suas vantagens não estão plenamente asseguradas. Enfim, essa dinâmica de reação e contrarreação desencadeia transformações profundas na ordem global, com resultados imprevisíveis. 


\section{REFERÊNCIAS BIBLIOGRÁFICAS}

ACIOLY, Luciana; PINTO, Eduardo C.; CINTRA, Marcos A. M. (2011) “China e Brasil: oportunidades e desafios”. In: LEÃO, Rodrigo; PINTO, Eduardo C.; ACIOLY, Luciana (Orgs.). A China na nova configuração global: impactos políticos e econômicos. Brasília: Ipea.

AGLIETTA, Michel (2015) “Ce que cachent les soubresauts financiers", Le Monde Diplomatique, Paris, octobre p. 4-5.

AGLIETTA, Michel; BAI, Guo. (2012) La voie chinoise: capitalisme et empire. Paris: Odile Jacob.

BIS - BANK FOR INTERNATIONAL SETTLEMENTS (2013) Triennial central bank survey foreign exchange turnover in April 2013. Basel: Monetary and Economic Department/BIS, September 2013.

BRESSER-PEREIRA, Luiz C. (2011) “China, 32 anos depois”. Folha de S.Paulo, 24 de abril de 2011.

CARVALHO, Carlos E. et al., (2015) "O banco e o arranjo de reservas do BRICS: iniciativas relevantes para o alargamento da ordem monetária e financeira internacional”, Estudos Internacionais. $\mathrm{BH}$ : PUC-MG.

CINTRA, Marcos A. M.; SILVA Filho, Edison B. (2015) "O sistema financeiro chinês: a Grande Muralha". In: CINTRA, Marcos A. M.; SILVA Filho, Edison B.; PINTO, Eduardo C. (Orgs.). China em transformação: dimensões econômicas e geopolíticas do desenvolvimento. Brasília, IPEA. p. 425-490.

CINTRA, Marcos A. M.; MARTINS, Aline R. A. (2013) "O papel do dólar e do renminbi no sistema monetário internacional”. In Cintra, Marcos, Martins, Aline R.A. (Orgs.). As transformações no sistema monetário internacional. Brasília, D.F.: Ipea. p. 211-321.

COHEN, Benjamin. (2012) "The yuan tomorrow? Evaluating China's currency internationalization strategy”, New Political Economy, vol. 17, n. 3, July.

DENG, Ping (2013) "Chinese outward direct investment research: theoretical integration and recommendations”. Management and Organization Review, vol. 9, n. 3, p. 513-539.

ECONOMIST (THE). (2015) "At a crossroad: what China's new economic diplomacy means for business". A report from The Economist Intelligence Unit, London.

ECONOMIST (THE) (2014) "Bridge over troubled water". London, November 15th.

ECONOMIST (THE). (2010) "Cover story: China buys up the world". London, November 13th p. 81-83.

EICHENGREEN, Barry; KAWAI, Masahiro (2015). Introduction and overview. In EICHENGREEN, Barry; KAWAI, Masahiro (Eds.). Renminbi internationalization: achievements, prospects, and challenges. Washington, Brookings Institution Press, February 11, p. 1-24.

FIORI, José L. (2013a) "Sobre o desenvolvimento chinês II", Valor Econômico, 27 de março de 2013.

FIORI, José L. (2013b) "Sobre o desenvolvimento chinês III” Valor Econômico, 24 de abril de 2013.

FIORI, José L. (2013c) “Sobre o desenvolvimento chinês IV”. Valor Econômico, 29 de maio de 2013.

GLOBAL Risk Insights. China: lender of first (and last) resort. April 30, 2015.

GRIFFITH-JONES, Stephany (2014) “A BRICS development bank: a dream coming true?” Geneva: United Nations Conference on Trade and Development (UNCTAD). Discussion Papers, n. 215.

GRIFFITH-JONES, Stephany; FRITZ, Barbara; CINTRA, Marcos A. M. (2014) "Novo banco de desenvolvimento". Valor Econômico, 21 de agosto de 2014.

HEILMANN, Sebastian; RUDOLF, Moritz; HUOTARI, Mikko; BUCKOW, Johannes.(2014) “China's shadow foreign policy: parallel structures challenge the established international order" Berlin: Mercator Institute for China Studies (Merics), 28 October . China Monitor, n. 18.

INTERNATIONAL MONETARY FUND - IMF (2015a)."Review of the method of valuation of the SDR - initial considerations", IMF Policy Paper, Washington, August 3, 2015

INTERNATIONAL MONETARY FUND - IMF (2015b). "Chinese Renminbi to be included in IMF's Special Drawing Right Basket”. Washington, December 1, 2015.

KISSINGER, Henry A. (2011) Sobre a China. Rio de Janeiro: Objetiva.

KISSINGER, Henry; FERGUSSON, Niall; ZAKARIA, Fareed; LI, David. (2012) O século XXI pertence à China? Um debate sobre a grande potência asiática. Rio de Janeiro: Ed. Elsevier \& Campus.

KROEBER, Arthur. (2015a) “The never-ending slowdown”, China Economic Quarterly, Beijing, November 2015.

KROEBER, Arthur (2015b). “Financing China's Global Dreams”, China Economic Quarterly, Beijing, November 2015. 
KROEBER, Arthur (2011). “The renminbi: the political economy of a currency”. Foreign policy, 7 September.

LONG, Chen (2016) "Capital flows and the currency endgame". Gavekal Dragonomics, Beijing, February 4,.

LONG, Chen (2015). Why RMB stability vs the US\$ matters. Gavekal Dragonomics. Beijing, February 03, $2015 \mathrm{a}$

MEDEIROS, Carlos A. Recursos naturais, nacionalismo e estratégias de desenvolvimento, Oikos, vol. 12, n. 2, Rio de Janeiro, 2013. p. 143-167.

MILLER, Tom. (2014) “A dream of Asian Empire”. Gavekal Dragonomics. December.

MILLER, Tom. (2015) “Maritime silk road or "string of pearls”?” Gavekal Dragonomics., April 23.

MINISTÉRIO da Fazenda (2014). Agreement on the New Development Bank. Fortaleza, 15 July 2014.

MORAES, Rodrigo F. (2015) "A ascensão naval chinesa e as disputas territoriais marítimas no Leste Asiático”. Rio de Janeiro, IPEA, março de 2015. Texto para Discussão, n. 2058.

NATIONAL Development and Reform Commission, Ministry of Foreign Affairs, and Ministry of Commerce of the People's Republic of China, with State Council authorization. Vision and actions on jointly building Silk Road Economic Belt and 21st-Century Maritime Silk Road, March 28, 2015.

NINIO, Marcelo (2015). “Chineses criam mundo espelhado que começa a mudar a ordem mundial”. Folha de S.Paulo, 11 de janeiro.

NOBLE, Josh (2015).”Renminbi joins top five most-used currencies". Financial Times, London, January 28.

OSTROUKH, Andrey. (2015) "Empresas russas receberão US\$ 25 bi de bancos chineses" The Wall Street Journal, republicado no Valor Econômico, São Paulo, 11 de maio.

PINTO, Eduardo C. (2011) “O eixo sino-americano e as transformações do sistema mundial.” In: LEÃO, Rodrigo; PINTO, Eduardo C.; ACIOLY, Luciana (Orgs.). A China na nova configuração global: impactos políticos e econômicos. Brasília: Ipea.

PINTO, Eduardo C.; GONÇALVES, Reinaldo (2014)."Les transformations mondiales et le nouveau rôle de la Chine". Revue Tiers Monde, vol. 219, p. 19-38.

POWER, Michael. (2015) “China's renminbi master plan sees Shanghai as a fountainhead of capital”. Financial Times, London, May 07.

SAFATLE, Claudia; RITTNER, Daniel. (2014) "Xi rejeita hegemonia e quer mais atuação em questões globais". Valor Econômico, São Paulo, 14 julho de 2014.

SEIB, Gerald F. (2015) "Para Obama, acordo comercial com Ásia pode reduzir influência da China", The Wall Street Journal, reproduzido no Valor Econômico, São Paulo, 28 de abril de 2015.

SINEDINO, Giorgio (Coord.) (2012) . Analectos. São Paulo, Editora Unesp.

SILVA, Luiz A. S. (2015) "Desafios ao crescimento da China e implicações das alterações recentes na sua política cambial”, Boletim de Economia e Política Internacional, n. 20. Brasília: IPEA, maio/ago.

SCHERER, André L. F. (2015) “ A nova estratégia de projeção geoeconômica chinesa e a economia brasileira”, Revista Paranaense de Desenvolvimento, v. 36, n. 129. Curitiba: IPARDES, Jul./Dez.

SWIFT. (2014) " 50 countries are now using the RMB for more than $10 \%$ of their payments value with China and Hong Kong”. Brussels, 26 November 2014. https://www.swift.com/insights/press-releases/50-countires-are-now-using-the-rmb-for-more-than-10_of-their-paments-value-with-china-and-hong-kong.

UEKI, Yasushi (2010). "Complementary manufacturing relationships between firms in China and CLMV". In: KAGAMI, Mitsuhiro (Ed.). Economic relations of China, Japan and Korea with the Mekong River Basin Countries (MBRCs). BRC Research Report No. 3, Thailand: Bangkok Research Center, IDE-JETRO, 2010, p. 328-363.

UNCTAD. (2014) World investment report - 2014. New York and Geneva: UNCTAD.

VU, Truong-Minh. (2014) "Between system maker and privileges taker: the role of China in the Greater Mekong Sub-region”. Revista Brasileira de Política Internacional, vol. 57, número especial, p. 157-173.

WHITE HOUSE (THE).( 2015) National Security Strategy. Washington, February.

WORLD BANK (THE) (2012) Development Research Center of the State Council. People's Republic of China. China 2030: building a modern, harmonious, and creative society. Washington: World Bank, 2012.

ZHANG, Zhiwei; SHI, Audrey (2015). China: RMB may become convertible in 2015. Hong-Kong, Deutsche Bank Research 7 April 2015, (Special Report). 